\section{RMD Open}

Rheumatic \&

Musculoskeletal Diseases

Bis: European

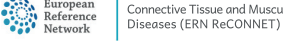

\title{
Relapsing polychondritis: state of the art on clinical practice guidelines
}

Simona Rednic, ${ }^{1}$ Laura Damian, ${ }^{1}$ Rosaria Talarico, ${ }^{2}$ Carlo Alberto Scirè, ${ }^{3}$ Alexander Tobias, ${ }^{4}$ Nathalie Costedoat-Chalumeau, ${ }^{5,6,7}$ David Launay, ${ }^{8}$ Alexis Mathian, ${ }^{9}$ Lisa Matthews, ${ }^{10}$ Cristina Ponte, ${ }^{11}$ Paola Toniati, ${ }^{12}$ Stefano Bombardieri, ${ }^{13}$ Charissa Frank, ${ }^{14}$ Matthias Schneider, ${ }^{15}$ Vanessa Smith, ${ }^{16,17}$ Maurizio Cutolo, ${ }^{18}$ Marta Mosca, ${ }^{2,19}$ Laurent Arnaud ${ }^{20}$
To cite: Rednic S, Damian L, Talarico R, et al. Relapsing polychondritis: state of the art on clinical practice guidelines. RMD Open 2018;4:e000788. doi:10.1136/ rmdopen-2018-000788

- Prepublication history for this paper is available online. To view these files, please visit the journal online (http://dx.doi. org/10.1136/rmdopen-2018000788)

SR and LD are co-authors.

Received 6 August 2018 Revised 31 August 2018 Accepted 7 September 2018

\section{Check for updates}

(c) Author(s) (or their employer(s)) 2018. Re-use permitted under CC BY-NC. No commercial re-use. See rights and permissions. Published by BMJ.

For numbered affiliations see end of article.

Correspondence to Professor Laurent Arnaud; laurent.arnaud@chrustrasbourg.fr

\section{ABSTRACT}

Due to the rarity of relapsing polychondritis (RP), many unmet needs remain in the management of RP. Here, we present a systematic review of clinical practice guidelines (CPGs) published for RP, as well as a list of the most striking unmet needs for this rare disease. We carried out a systematic search in PubMed and Embase based on controlled terms (medical subject headings and Emtree) and keywords of the disease and publication type (CPGs). The systematic literature review identified 20 citations, among which no CPGs could be identified. We identified 11 main areas with unmet needs in the field of RP: the diagnosis strategy for RP; the therapeutic management of $\mathrm{RP}$; the management of pregnancy in RP; the management of the disease in specific age groups (for instance in paediatric-onset RP); the evaluation of adherence to treatment; the follow-up of patients with RP, including the frequency of screening for the potential complications and the optimal imaging tools for each involved region; perioperative and anaesthetic management (due to tracheal involvement); risk of neoplasms in RP, including haematological malignancies; the prevention and management of infections; tools for assessment of disease activity and damage; and patient-reported outcomes and quality of life indicators. Patients and physicians should work together within the frame of the ReCONNET network to derive valuable evidence for obtaining literatureinformed CPGs.

\section{INTRODUCTION}

Relapsing polychondritis (RP) is a systemic inflammatory disease primarily affecting the cartilaginous structures of the ears, nose and tracheobronchial tree, but also the joints, the inner ear, the eyes and the cardiovascular system. ${ }^{1}$ The first case of RP was described in 1923 by Jaksch-Wartenhorst, ${ }^{2}$ but little attention has been given to the entity until the 1960 s, when Pearson et $a l^{3}$ introduced the name 'relapsing polychondritis'. The classification criteria for RP by Michet et $a l^{4}$ require the presence of proven inflammation in at least two of
Key messages

What is already known about this subject?

- Due to the rarity of the disease and the paucity of available evidence, many unmet needs remain in the field of relapsing polychondritis (RP).

What does this study add?

- We performed a systematic review of clinical practice guidelines published for RP, and we identified the most striking unmet needs in this rare disease.

How might this impact on clinical practice?

- Due to the extreme rarity of the disease, patients and physicians should work together within the frame of the ReCONNET network to derive valuable evidence for informing literature-based clinical practice guidelines for RP.

three of the auricular, nasal or laryngotracheal cartilages, or proven inflammation in one cartilage plus two other signs, including ocular inflammation, vestibular dysfunction, seronegative inflammatory arthritis or hearing loss. RP is a chronic disease with a flaring-remitting course. The exact cause of $\mathrm{RP}$ is still unknown, but the disease is mostly regarded as an immune-mediated disease, as there is a well-documented overlap of RP with other rheumatic and autoimmune diseases. ${ }^{4}{ }^{6}$ Moreover, RP is strongly associated with the Human Leucocyte Antigen (HLA) allele DR4, and various immune responses directed against cartilage components have been demonstrated in patients with RP. ${ }^{5}$ Since RP is a very rare disease, with a prevalence estimated to be as low as a few cases per million, ${ }^{78}$ it remains an under-researched area. Scores for assessing both disease activity and damage in RP have been developed by our group, with the help of a panel of international experts. ${ }^{9}$ Importantly, due to the rarity of the disease, the lack of 


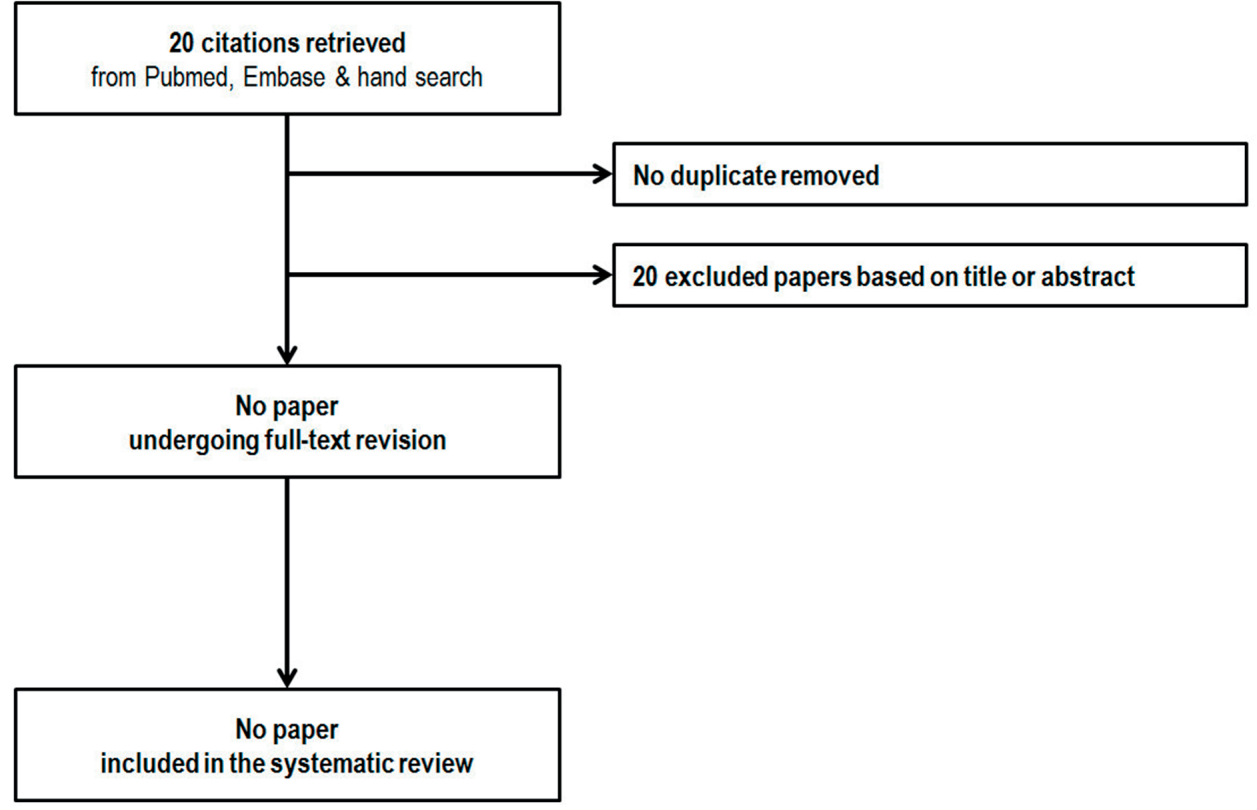

Figure 1 Flow chart showing the study selection process.

adequate networks of care for RP in most countries and the paucity of drug efficacy data, many unmet needs remain in the field of RP. Here we present a systematic review of clinical practice guidelines (CPGs) published for RP, as well as a list of the most striking unmet needs in this rare disease. The review has been carried out under the framework of the European Reference Network on Rare and Complex Connective Tissue and Musculoskeletal Diseases (ERN ReCONNET), gathering the experience of several European centres with experience in the diagnosis and follow-up of RP and involving patient representatives.

\section{METHODS}

We carried out a systematic search in PubMed and Embase based on controlled terms (medical subject headings (MeSH) and Emtree) and keywords of the disease and publication type (CPGs). We reviewed all the published articles in order to identify existing CPGs on diagnosis, monitoring and treatment, according to the definition of the Institute of Medicine 2011 (CPGs are statements that include recommendations intended to optimise patient care that are informed by a systematic review of evidence and an assessment of the benefits and harms of alternative care options). The disease coordinator (DC) of the ERN ReCONNET for RP has assigned the work on CPGs to the healthcare providers involved. Moreover, in order to implement the list of guidelines provided by the Medline and Embase search, the group also performed a hand search. A first screening among papers included in the final list (systematic search + hand search) based on title and abstract selected evidence-based medicine guidelines. A general assessment of the CPGs has been performed following the Appraisal of Guidelines for Research \&
Evaluation II (AGREE II) tool checklist not for formal appraisal but only to inform discussion. A discussion group was set for the evaluation of the existing CPGs and to identify the unmet needs.

Here is the search strategy: Medline (PubMed): ("polychondritis, relapsing" [MeSH Terms] OR ("polychondritis" [All Fields] AND "relapsing" [All Fields]) OR "relapsing polychondritis" [All Fields] OR ("relapsing" [All Fields] AND "polychondritis" [All Fields]) AND ("Practice Guideline" [Publication Type] OR "Practice Guidelines As Topic" [MeSH Terms] OR Practice Guideline [Publication Type] OR "Practice Guideline" [Text Word] OR "Practice Guidelines" [Text Word] OR "Guideline" [Publication Type] OR "Guidelines As Topic" [MeSH Terms] OR Guideline [Publication Type] OR "Guideline" [Text Word] OR "Guidelines" [Text Word] OR "Consensus Development Conference" [Publication Type] OR "Consensus Development Conferences As Topic" [MeSH Terms] OR "Consensus" [MeSH Terms] OR "Consensus" [Text Word] OR "Recommendation" [Text Word] OR "Recommendations" [Text Word] OR "Best Practice" [Text Word] OR "Best Practices" [Text Word]). Embase: ('relapsing polychondritis'/exp OR 'atrophic polychondritis' OR 'chronic atrophic polychondritis' OR 'chronic atropic polychondritis' OR 'chronic polychondritis, atrophic' OR 'polychondritis, relapsing' OR 'relapsing polychondritis') AND ('practice guideline'/exp OR 'practice guideline' OR 'practice guidelines'/exp OR 'practice guidelines' OR 'clinical practice guideline'/exp OR 'clinical practice guideline' OR 'clinical practice guidelines'/exp OR 'clinical practice guidelines' OR 'clinical practice guidelines as topic'/exp OR 'clinical practice guidelines as topic' OR 'guideline'/exp OR 'guideline' OR 'guidelines'/exp OR 'guidelines' OR 'guidelines as topic'/exp OR 'guidelines as topic' OR 'consensus development'/exp OR 'consensus development' OR 'consensus development conference'/exp OR 'consensus development conference' OR 'consensus development conferences'/ 
Box 1 Unmeet needs in the field of relapsing polychondritis (RP)

Major unmet needs in the field of RP.

- The diagnosis strategy for RP.

- The therapeutic management of RP.

- The management of pregnancy in RP.

- The management of the disease in specific age groups (for instance in paediatric-onset RP and its relationship with growth, or in the geriatric population).

- The evaluation and management of adherence to treatment.

- The follow-up of patients with RP, including the frequency of screening for the potential complications, mainly of respiratory, cardiac, aortic, ocular and joint involvement, and the optimal imaging tools for each involved region.

- Perioperative and anaesthetic management (due to tracheal involvement).

- Risk of neoplasms in RP, including haematological malignancies, and the need for screening for an occult neoplasm.

- The prevention and management of infections.

Tools for assessment of disease activity and damage.

Patient-reported outcomes and quality of life indicators.

exp OR 'consensus development conferences' OR 'consensus development conferences as topic'/exp OR 'consensus development conferences as topic' OR 'consensus'/exp OR 'consensus' OR 'recommendation' OR 'recommendations') AND [embase]/ lim NOT [medline]/lim.

\section{RESULTS}

\section{State of the art on CPGs}

The systematic literature review identified 20 citations, among which no CPGs could be identified (figure 1).

\section{Unmet needs}

Clinicians' unmet needs

Following extensive discussions between the DC and other members of the ReCONNET network, we identified 11 main areas with unmet needs in the field of RP (box 1). We also report detailed list of clinical manifestations that may be seen in RP (table 1).

\section{The diagnostic strategy for $R P$}

The classical classification criteria for RP (such as those by Michet $e t a l,{ }^{4}$ McAdams or Damiani-Levine) have been empirically postulated. The disease is rare and difficult to recognise early, especially in the absence of typical cartilage involvement. The diagnostic delay is associated with the lack of ear, nose or joint involvement. ${ }^{10-13}$ Early signs of RP in such cases may be intermittent arthritis or eye involvement such as episcleritis and scleritis, which may point a search for RP. However, even in the presence of external ear inflammation, an infection, local trauma, insect bite and chondrodermatitis nodularis helicis (Winkler's disease) are often suspected first.

The diagnosis of RP is mostly clinical, and may be informed by laboratory data, imaging techniques and occasionally cartilage biopsies. RP mimickers such as granulomatosis with polyangiitis (GPA), T-cell lymphoma, sarcoidosis and so on have to be differentiated from RP. Moreover, another immune-mediated disease, such as systemic lupus erythematosus, Sjogren's syndrome, vasculitis, antiphospholipid syndrome, rheumatoid arthritis, spondyloarthritis, inflammatory bowel disease, thyroiditis and others, is associated with RP in up to $30 \%$ of cases and should be searched for systematically. On diagnosis, a baseline assessment is necessary in order to evaluate disease activity, organ involvement and disease damage, and to identify potentially associated diseases. A typical baseline assessment may include otorhinolaryngology and ophthalmology examinations, cardiovascular screening for valvulopathies and aortic involvement, pulmonary assessment, renal function testing, testing for antineutrophil cytoplasmic autoantibodies (ANCAs) and possibly haematological assessment to rule out myelodysplastic syndrome (MDS).${ }^{14}$ However, the frequency of these assessments is not standardised and may require further validation.

To date, there is a real need for validated diagnostic biomarkers in RP, as well as markers predictive of disease activity, specific organ involvement or prognosis. There is no characteristic laboratory analysis in RP. An inflammatory syndrome is present in more than $60 \%$ of patients, but is not constant during flares. ${ }^{15}$ Antinuclear antibodies with no particular specificity and ANCA, mostly atypical in immunofluorescence, with no proteinase 3 (PR3) or myeloperoxidase (MPO) specificity, have been reported in several series. ${ }^{15}$ The potential candidate biomarkers, the anticollagen type II antibodies and antimatrilin type I antibodies, are neither sensitive nor specific enough. ${ }^{11416}$ Moreover, cartilage biopsy is positive only in two-thirds of cases and does not show any specific change ${ }^{315} 17$; its added value is therefore limited.

Several potential disease activity markers such as anticollagen type II antibodies, antimatrilin-I antibodies, other autoantibodies targeting collagen structures (serum cartilage oligomeric matrix protein, urinary type II collagen neoepitope) or interferon-gamma, interleukin (IL)-12 and IL-2 and serum soluble triggering receptor expressed on myeloid cells 1 (sTREM-1) have been reported to parallel the flares. ${ }^{5}$ None of these have entered clinical practice.

Mortality in RP is more than double compared with the general population; the most frequent causes of death are respiratory, cardiac and haematological involvement. ${ }^{12}$ Three phenotypes with different presentations have been recently described in a cluster analysis of a cohort: a haematological form (in 10\% of cases), a respiratory form (in 25\%) and a mild one with good prognosis (about $65 \%$ of cases).$^{15}$ Some complications such as aortitis ${ }^{18}$ vasculitis ${ }^{4}$ or anaemia are pejorative prognosis factors. ${ }^{4}$ In addition, the male gender is associated with worse prognosis and higher prevalence of uveitis, hearing loss, vestibular disorder, as well as greater necessity for methylprednisolone and cyclophosphamide pulses. ${ }^{19}$ 
Table 1 Main clinical features of RP and proposed management (expert opinion)

\begin{tabular}{|c|c|}
\hline Main clinical manifestations & Typical therapeutic management* (based on expert opinion) \\
\hline $\begin{array}{l}\text { Nasal or auricular chondritis. } \\
\text { Peristernal chondritis. }\end{array}$ & $\begin{array}{l}\text { NSAIDs, GCs. In case of relapsing disease colchicine, dapsone, methotrexate or other } \\
\text { conventional immunosuppressive agents or biologics. }\end{array}$ \\
\hline Tracheal chondritis. & $\begin{array}{l}\text { GCs, methylprednisolone infusion, csDMARDs, conventional immunosuppressive } \\
\text { agents (eg, cyclophosphamide) or biologics. }\end{array}$ \\
\hline $\begin{array}{l}\text { Articular manifestations. } \\
\text { Peripheral and/or axial involvement. }\end{array}$ & $\begin{array}{l}\text { NSAIDs, GCs, csDMARDs, conventional immunosuppressive agents (eg, methotrexate } \\
\text { or biologics. }\end{array}$ \\
\hline $\begin{array}{l}\text { Cutaneous involvement. } \\
\text { Aphtosis. } \\
\text { Nodules. } \\
\text { Cutaneous vasculitis. }\end{array}$ & GCs, colchicine, dapsone (especially in case of neutrophilic dermatitis), methotrexate. \\
\hline $\begin{array}{l}\text { Cardiac involvement. } \\
\text { Valvular involvement. } \\
\text { Pericarditis. } \\
\text { - Myocarditis. } \\
\text { - Aortitis. }\end{array}$ & $\begin{array}{l}\text { GCs, csDMARDs, conventional immunosuppressive agents (eg, methotrexate) or } \\
\text { biologics. }\end{array}$ \\
\hline $\begin{array}{l}\text { Ocular involvement. } \\
\text { Episcleritis. } \\
\text { Scleritis. }\end{array}$ & $\begin{array}{l}\text { Topical GCs, cycloplegic. All patients with ocular involvement should be referred to an } \\
\text { ophthalmologist. csDMARDs, conventional immunosuppressive agents or biologics } \\
\text { may be necessary. }\end{array}$ \\
\hline $\begin{array}{l}\text { Audiovestibular dysfunction. } \\
\text { Sensorineural deafness. } \\
\text { Vestibular dysfunction. }\end{array}$ & $\begin{array}{l}\text { GCs, methylprednisolone infusion, csDMARDs, conventional immunosuppressive } \\
\text { agents or biologics. }\end{array}$ \\
\hline $\begin{array}{l}\text { Neurological manifestations. } \\
\text { Sensorimotor neuropathy. } \\
\text { Encephalitis. }\end{array}$ & $\begin{array}{l}\text { GCs, methylprednisolone infusion, csDMARDs, conventional immunosuppressive } \\
\text { agents (eg, cyclophosphamide) or biologics. }\end{array}$ \\
\hline Renal involvement. & $\begin{array}{l}\text { In most cases, renal involvement suggests differential diagnoses such as ANCA- } \\
\text { associated vasculitis. }\end{array}$ \\
\hline
\end{tabular}

${ }^{*}$ The proposed therapeutic strategy should take into account disease severity and patient individual characteristics/contact one of the ReCONNET centre for RP when appropriate.

ANCA, antineutrophil cytoplasmic autoantibodies; GCs, glucocorticoids;NSAIDs, non-steroidal anti-inflammatory drugs; RP, relapsing polychondritis; csDMARDs, conventional synthetic disease-modifying antirheumatic drugs.

\section{The therapeutic management of $R P$}

The treatment in RP is mostly based on case reports and case series. The therapy is selected according to the clinical picture and its severity, and depends on the type of organ involvement. Minor nasal or auricular chondritis may respond to non-steroidal anti-inflammatory drugs, glucocorticoids, ${ }^{11}$ colchicine or dapsone. Conventional disease-modifying antirheumatic drugs (cDMARDs) are employed as glucorticoid-sparing agents or in cases of more severe disease: methotrexate, azathioprine, ciclosporin, leflunomide, mycophenolate mofetil, cyclophosphamide and so on, sometimes in a ladder-step increment. ${ }^{11}$ No clinical trials have been published on biologics in RP. ${ }^{11}{ }^{20}$ In a recent French series, ${ }^{21}$ the biologic agents used to treat RP included tumour necrosis factor inhibitors (among which adalimumab was shown to have the best remanence), tocilizumab, anakinra, rituximab and abatacept.

Strikingly, only $2 / 3$ of patients responded to treatment at 6 months, with a complete response observed in 19\% of cases.

The management of eye involvement is critical, because necrotising scleritis is commonly associated with significant morbidity and may lead to ocular perforation.
Patients should be referred to an ophthalmologist as early start of local and systemic therapy may avoid further complications. While minor cases such as episcleritis may be managed using topical treatments, the most severe cases usually prompt aggressive systemic treatment such as glucocorticoid and cyclophosphamide infusions. Cases of necrotising scleritis treated with biologics (infliximab or adalimumab) have also been reported. ${ }^{10}{ }^{11}$ The use of cyanoacrylate glue repairment has been reported for peripheral corneal perforations. ${ }^{22}$

The management of respiratory airway involvement depends on its presentation and severity. About 25\% of cases will develop a laryngotracheal stricture. ${ }^{23}$ Early signs of tracheobronchomalacia should be searched for. Tracheal narrowing can be addressed by tracheostomy, tracheal dilation, stenting and reconstructive surgery. ${ }^{11}$ However, it is not clear whether these procedures do not aggravate RP, as they may result in distal airway inflammation. ${ }^{14}$ Due to the risk of tracheal perforation, pulmonary fibroscopy should generally be strongly discouraged in RP. When absolutely needed, the procedure should be performed only by very skilled pneumologists, with the backup of an intensive care unit. Nasal reconstructive surgery has controversial results; bone grafts are mostly 
preferred (skull or iliac bone) since common cartilage may become inflamed after trauma; however L-shaped costal cartilage has been employed successfully in disease remission under immunosuppressants. ${ }^{14} 24$

The management of arthritis is also non-codified. In most cases, the episodes of arthritis are self-limited and non-erosive and its occurrence does not parallel other disease features. The costochondral, sternoclavicular and manubriosternal joints, as well as the peripheral large and small joints, may be involved, sometimes in an asymmetric manner. ${ }^{25}$ cDMARDs, sometimes in combination with biologic therapy, may be required.

In a recent large study, aortic involvement, consisting of aneurysms or ectasia, mainly of the thoracic and abdominal aorta, occurred in $6.4 \%$ of cases, after a median follow-up of 2 years. ${ }^{18}$ An older study showed that a close vascular follow-up is needed in RP and that reintervention may be necessary in some cases. ${ }^{26}$ In a recent series, up to $22 \%$ of patients had a cardiac valvulopathy, usually not severe. ${ }^{15}$ Periodic echocardiography may detect the progression of a valvulopathy despite the apparent quiescence of RP. ${ }^{27}$

The existence of a renal involvement is a controversial issue in RP, because in most cases the correct diagnosis is not RP but GPA or microscopic polyangiitis. ${ }^{15}$

The skin involvement is non-specific, including neutrophilic dermatosis, cutaneous vasculitis, nodules, aphthae, superficial venous thrombosis and so on. Chronic skin lesions are more frequent in patients with late-onset RP and are associated with MDS. ${ }^{28} 29$

\section{The management of pregnancy in RP}

The management of pregnancy in RP relies on scarce data. In a case series of 25 pregnancies in 11 women, 1 elective medical termination was performed due to cyclophosphamide therapy; flares occurred in 7 of the remaining 24 cases, while the disease was considered stable in 16 cases and asymptomatic in $1 .{ }^{30} \mathrm{RP}$ onset during pregnancy, at about 20 weeks of gestation, has also been published. No evidence of neonatal RP was observed in neonates, but the risk of fetal loss was increased. ${ }^{30}$

\section{$R P$ in specific age groups}

A systematic review of paediatric-onset RP identified the most common presenting features to be joint pain, ocular inflammation and chondritis. ${ }^{31}$ Paediatric RP shares many features with adult RP; however, children frequently have a familial history of autoimmunity and usually do not have associated autoimmune diseases. The outcome may be fatal, mostly due to cardiac complications; hence, the screening for complications is mandatory. Growth does not seem to be impaired by cartilage involvement, ${ }^{31}$ although there are exceptions with regard to the epiphysia plate involvement and destructive arthritis. ${ }^{32}$ Increased MRI bone marrow signal of unclear significance has been reported in two children. ${ }^{33}$ In very young children, the monogenic autoinflammatory disease chronic atypical neutrophilic dermatosis with lipodystrophy and elevated temperature (CANDLE) proteasome-associated autoinflammatory syndrome (PRAAS) (CANDLE (PRAAS)) due to proteasome mutations (PSMB8) may evolve with polychondritis features (auricular chondritis, nodular episcleritis and keratitis, along with widespread inflammation and lipodystrophy). ${ }^{34}$

In the elderly, the presence of chondritis may point to an associated vasculitis or to an MDS, more frequent in this age group. Previous age-related cardiac and respiratory involvement may affect the prognosis in the presence of silent valvular or respiratory disease due to RP. ${ }^{15}$

\section{The evaluation and management of adherence to treatment}

There are no data referring to the adherence to therapy and its evaluation in patients with RP. ${ }^{19}$ This issue needs to be addressed, mostly in patients with a refractory disease that fails to respond to conventional therapy.

\section{The follow-up and the optimal imaging tool}

Follow-up of patients with RP includes screening for potential complications, mainly of respiratory, cardiac, aortic, ocular and joint involvement, as well as a proactive assessment of complications (at least respiratory, cardiac, ocular and otorhinolaryngological). The optimal frequency of the assessment is not known. However, in a recent study, aortic complications were detected at $\approx 2$ years from diagnosis. ${ }^{18}$ Arthritis and the ocular features may be inaugural or may appear anytime during the disease. For respiratory involvement, a thorax CT scan ${ }^{35}$ may reveal oedematous tracheobronchial wall thickening with or without mural calcifications, deformity of cartilaginous structures, and narrowing of the trachea and bronchi. A typical feature is that the posterior part of the trachea (membranous trachea) is usually spared in case of early tracheal involvement, which is suggestive of RP. Dynamic examinations may reveal air structures collapse. ${ }^{13}$ CT scan of the neck may reveal thickening, calcification or destructive lesions of the larynx cartilages (such as cricoid or thyroid cartilage) ${ }^{36}$ Thoracoabdominal CT scan identifies the aortic involvement. ${ }^{18}$ Also not fully validated, several reports suggest that 18F-fluorodeoxyglucose Positron Emission Tomography (18F-FDG PET/CT) could be interesting for therapeutic response monitoring as the uptake may diminish or disappear after therapy. ${ }^{37}$ For articular involvement, Tc- $99 \mathrm{~m}$ bone scintigraphy may reveal active sites of inflammation. ${ }^{38}$ Cerebral MRI may be useful if central nervous system involvement is suspected. ${ }^{39}$ Otorhinolaryngoscopic examination reveals conductive and sensorineural hearing loss in about $40 \%$ of cases, sometimes along with nasal ulcerations, septal perforations, saddle nose deformity, arytenoid swelling and vocal cords deformities. ${ }^{13}$ Pulmonary spirometry, including inspiratory volumes, may help assess the tracheal involvement. Ophthalmoscopic examination may reveal any type of structure involvement (conjunctivitis, episcleritis, keratitis, uveitis, retinopathy, glaucoma, dacryocystitis and so on), the most dreaded being necrotising scleritis or 
peripheral ulcerative keratitis, which may rapidly lead to eye loss. ${ }^{1}$

\section{Perioperative and anaesthetic management}

In case of surgery, the anaesthesiologist should be informed of the risk of airway damage during intubation, ${ }^{40}$ tracheal stenosis or tracheobronchomalacia, strictures and scars in the cricoarytenoid area, or dynamic airway obstruction. ${ }^{40}$ Anaesthesia may be converted to epidural analgesia whenever possible. A careful preoperative assessment should be planned and the anaesthesiologist may need to prepare various sizes of tracheal tubes and other airway manipulation devices. ${ }^{41}$

\section{The risk of neoplasms}

Haematological malignancies, mainly MDS, but also lymphoma including mucosa-associated lymphoid tissue, myeloproliferative neoplasms, multiple myeloma and others, and more rarely solid cancers (lung, breast, colon, urothelial carcinoma, sarcoma), have been described in $11 \%-13 \%$ of cases, mainly in male patients with lateonset RP ( $>60$ years) and in those with cutaneous involvement, mostly neutrophilic dermatosis. ${ }^{152842}$ The reasons for this association are still occult. There are no guidelines regarding the type and frequency of screening for occult neoplasia in RP. ${ }^{43}$ Exophthalmos in patients with RP should prompt the search for lymphoma or IgG4associated disease. $^{44}$

\section{The prevention and management of infections}

Infections are responsible for the significant morbidity (up to $35 \%$ ) in the respiratory phenotype patients. ${ }^{15}$ Secretion clearance is impaired in patients with airway involvement. In addition, the risk of infections is higher in patients with an underlying MDS or diabetes. Steroids and biologic therapy administration may be complicated by systemic infections in such patients (45). There are no guidelines regarding infection prophylaxis and therapy in patients with RP, but it is reasonable to believe that the general recommendations used in immunocompromised patients should apply in patients with RP with immunosuppressive treatments.

\section{Tools for assessment of disease activity and damage}

As RP is a remitting-relapsing disease, disease activity has to be recorded during follow-up. The Relapsing Polychondritis Disease Activity Index (RPDAI) has been designed to assess RP in a standardised manner, taking into account the disease manifestations over a 28-day period. The RPDAI consists of 27 items with individual weights, ranging from 1 to 24 , and reaches a maximum theoretical score of $265 .^{9}$ More important, as there are no biologic disease activity markers in use, the RPDAI is a useful instrument to assess disease activity in multiple systems, as well as to assess therapeutic response, even in patients with no current inflammatory syndrome (table 2). A damage index has been recently developed (Arnaud 2018, in press) to assess the diseaseinduced irreversible changes, with the aim to standardise the assessment and to facilitate studies in this rare disease.
Table 2 The Relapsing Polychondritis Disease Activity Index (RPDAI), adapted from Arnaud et al ${ }^{9}$

\begin{tabular}{|c|c|c|c|}
\hline Points & & Points & \\
\hline & Constitutional symptoms & & $\begin{array}{l}\text { Cutaneous } \\
\text { manifestations }\end{array}$ \\
\hline \multirow[t]{2}{*}{2} & Fever $\left(>38^{\circ} \mathrm{C} / 100.4^{\circ} \mathrm{F}\right)$ & 3 & Purpura \\
\hline & $\begin{array}{l}\text { Rheumatological } \\
\text { manifestations }\end{array}$ & & $\begin{array}{l}\text { Renal } \\
\text { manifestations }\end{array}$ \\
\hline \multirow[t]{2}{*}{1} & Arthritis & 4 & Haematuria \\
\hline & Chondritides & 6 & Proteinuria \\
\hline 3 & $\begin{array}{l}\text { Manubriosternal } \\
\text { chondritis }\end{array}$ & 17 & Renal failure \\
\hline 4 & $\begin{array}{l}\text { Sternoclavicular } \\
\text { chondritis }\end{array}$ & & $\begin{array}{l}\text { Cardiovascular } \\
\text { manifestations }\end{array}$ \\
\hline 4 & Costochondritis & 9 & Pericarditis \\
\hline 9 & $\begin{array}{l}\text { Auricular chondritis (can } \\
\text { be unilateral or bilateral) }\end{array}$ & 16 & $\begin{array}{l}\text { Large-sized and/ } \\
\text { or medium- } \\
\text { sized vessel } \\
\text { involvement }\end{array}$ \\
\hline \multirow[t]{2}{*}{9} & Nasal chondritis & 17 & Myocarditis \\
\hline & $\begin{array}{l}\text { Ophthalmological } \\
\text { manifestations }\end{array}$ & 18 & $\begin{array}{l}\text { Acute aortic or } \\
\text { mitral insufficiency }\end{array}$ \\
\hline 5 & Episcleritis & & $\begin{array}{l}\text { Neurological } \\
\text { manifestations }\end{array}$ \\
\hline 9 & Scleritis & 12 & $\begin{array}{l}\text { Motor or } \\
\text { sensorimotor } \\
\text { neuropathy }\end{array}$ \\
\hline 9 & Uveitis & 22 & Encephalitis \\
\hline 11 & Corneal ulcer & & $\begin{array}{l}\text { Respiratory } \\
\text { manifestations }\end{array}$ \\
\hline \multirow[t]{2}{*}{14} & Retinal vasculitis & & $\begin{array}{l}\text { Respiratory } \\
\text { chondritis (laryngeal } \\
\text { and/or tracheal } \\
\text { and/or bronchial } \\
\text { chondritis) }\end{array}$ \\
\hline & Biological data & 14 & $\begin{array}{l}\text { Without acute } \\
\text { respiratory failure }\end{array}$ \\
\hline \multirow[t]{2}{*}{3} & $\begin{array}{l}\text { Raised C reactive } \\
\text { protein (>20 mg/L) }\end{array}$ & 24 & $\begin{array}{l}\text { With acute } \\
\text { respiratory failure }\end{array}$ \\
\hline & ENT manifestations & & $\begin{array}{l}\text { Other (please } \\
\text { explain): }\end{array}$ \\
\hline 8 & Sensorineural deafness & & \\
\hline \multirow[t]{2}{*}{12} & Vestibular dysfunction & & \\
\hline & & & $\begin{array}{l}\text { TOTAL RPDAI } \\
\text { SCORE }\end{array}$ \\
\hline
\end{tabular}

The scoring should only take into account manifestations attributable to relapsing polychondritis and present during the last 28 days. ENT, ear, nose and throat.

\section{Patient-reported outcomes and quality of life indicators}

A recent study on more than 300 patients revealed that over $50 \%$ have visited the emergency room, had symptoms for more than 5 years and have consulted more than three physicians prior to diagnosis. ${ }^{13}$ The diagnostic delay $(>1$ year) was attributed to coexisting fibromyalgia and to the lack of auricular and nasal chondritis and arthritis. ${ }^{13}$ Some patients may need long-term glucocorticoids and therefore 
develop complications associated with the therapy (arterial hypertension, diabetes mellitus and so on). ${ }^{19}$ Disease burden is high and includes disability (25\%), hearing loss (34\%) more prevalent in patients with joint involvement, and tracheomalacia $(16 \%)$ in patients with respiratory involvement. From this perspective, relevant unmet needs are timely diagnosis, standards for therapy, and prevention of disease-related and therapy-related complications. ${ }^{13}$ No self-reporting instruments for patients with RP are available; there are no data regarding the quality of life indicators in patients with RP. Both the RPDAI and the Relapsing Polychondritis DAmage Index (RPDAM) have been derived using the Delphi method and/or patient case exercises, as well as using additional feedback from international experts. Those have not been validated prospectively and their detailed psychometric properties, including sensitivity to change and minimal clinically important difference, remain currently unknown.

\section{Patients' unmet needs}

Most patients are in need of a continuity of care and follow-up, in particular through a multidisciplinary team approach. When there is extensive RP damage, many different appointments are needed for different specialists who do not always communicate with each other or are aware of the disease. There is also a need for a better diagnostic approach, as well as a team that helps patients after the diagnosis with reasonable adjusted advice about employment and disability. It is mainly the care and therapeutic approach that is of most importance for patients. There is a lack of knowledge, not enough studies available, as well as no specialised clinical and research teams available for most patients. RP damage can have a big impact on the well-being of patients. The patients, caregivers and medical caregivers therefore need to be further educated to help in the assistance of patients with RP. The ERN ReCONNET could help play a major role in this matter.

\section{CONCLUSION}

This systematic review shows that there are currently no CPGs available for RP. Given the limited data on the pathogenesis of the disease, the association of clinical and laboratory manifestations or imaging strategies, we were able to identify several major unmet needs. To the extreme rarity of the disease, patients and physicians should work together within the frame of the ReCONNET network to derive valuable evidence for the derivation of literatureinformed CPGs.

\author{
Author affiliations \\ ${ }^{1}$ Department of Rheumatology, Emergency County Teaching Hospital, Cluj-Napoca, \\ Romania \\ ${ }^{2}$ Rheumatology Unit, AOU Pisana, Pisa, Italy \\ ${ }^{3}$ Department of Medical Sciences, Section of Rheumatology, University of Ferrara, \\ Ferrara, Italy \\ ${ }^{4}$ Department of Rheumatology and Clinical Immunology, Charité University Hospital \\ Berlin, Berlin, Germany \\ ${ }^{5}$ Assistance Publique-Hôpitaux de Paris (AP-HP), Cochin Hospital, Internal Medicine \\ Department, Referral Center for Rare Autoimmune and Systemic Diseases, Paris, \\ France
}

${ }^{6}$ Paris Descartes-Sorbonne Paris Cité University, Paris, France ${ }^{7}$ INSERM U 1153, Center for Epidemiology and Statistics Sorbonne Paris Cité (CRESS), Paris, France

${ }^{8}$ Département de Médecine Interne et Immunologie Clinique, Centre de Référence des Maladies Systémiques et Auto-Immunes Rares du Nord-Ouest (CERAINO), LIRIC, INSERM, Univ. Lille, CHU Lille, Lille, France

${ }^{9}$ Department of Internal Medicine, Hospital Pitié-Salpêtrière, Assistance PubliqueHôpitaux de Paris, Paris, France

${ }^{10}$ Relapsing Polychondritis Awareness and Support, Worcester, UK

${ }^{11}$ Department of Rheumatology, Hospital de Santa Maria, Centro Hospitalar Lisboa Norte, Lisbon Academic Medical Centre, Lisbon, Portugal

${ }^{12}$ Rheumatology and Clinical Immunology Unit, Civil Hospital, Brescia, Italy

${ }^{13}$ University of Pisa, Pisa, Italy

${ }^{14}$ Bindweefsel.be, Koersel, Belgium

${ }^{15}$ Department of Rheumatology, Universitätsklinikum Düsseldorf, Düsseldorf, Germany

${ }^{16}$ Department of Rheumatology, Ghent University Hospital, Ghent, Belgium

${ }^{17}$ Department of Internal Medicine, Ghent University, Ghent, Belgium

${ }^{18}$ Research Laboratory and Academic Division of Clinical Rheumatology, Department of Internal Medicine, IRCCS Polyclinic Hospital San Martino, University of Genoa, Genoa, Italy

${ }^{19}$ Rheumatology Unit, University of Pisa, Pisa, Italy

${ }^{20}$ Service de rhumatologie, Hôpitaux Universitaires de Strasbourg, Centre National de Référence des Maladies Systémiques et Auto-immunes Rares (RESO), INSERMUMRS 1109, F-67000, Strasbourg, France

Contributors All the authors contributed to the manuscript.

Funding This publication was funded by the European Union's Health Programme (2014-2020).

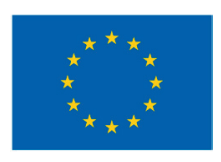

Disclaimer ERN ReCONNET is one of the 24 European Reference Networks (ERNs) approved by the ERN Board of Member States. The ERNs are co-funded by the European Commission. The content of this publication represents the views of the authors only and it is their sole responsibility; it cannot be considered to reflect the views of the European Commission and/or the Consumers, Health, Agriculture and Food Executive Agency (CHAFEA) or any other body of the European Union. The European Commission and the Agency do not accept any responsibility for use that may be made of the information it contains. Competing interests None declared.

Patient consent Not required.

Provenance and peer review Commissioned; externally peer reviewed.

Data sharing statement Data can be accessed by contacting the main author, upon reasonable request.

Open access This is an Open access article distributed in accordance with the Creative Commons Attribution Non Commercial (CC BY-NC 4.0) license, which permits others to distribute, remix, adapt, build upon this work non-commercially, and license their derivative works on different terms, provided the original work is properly cited, appropriate credit is given, any changes made indicated, and the use is non-commercial. See: http://creativecommons.org/licenses/by-nc/4.0/.

\section{REFERENCES}

1. Lahmer T, Treiber M, von Werder A, et al. Relapsing polychondritis: an autoimmune disease with many faces. Autoimmun Rev 2010;9:540-6.

2. Jaksch-Wartenhorst R. Polychondropathia. Wien Arch F Inn Med 1923;6:93-100.

3. Pearson CM, Kline HM, Newcomer VD. Relapsing polychondritis. $N$ Engl J Med 1960;263:51-8.

4. Michet CJ, McKenna CH, Luthra HS, et al. Relapsing polychondritis. Survival and predictive role of early disease manifestations. Ann Intern Med 1986;104:74-8.

5. Arnaud L, Mathian A, Haroche J, et al. Pathogenesis of relapsing polychondritis: a 2013 update. Autoimmun Rev 2014;13:90-5.

6. Ludvigsson JF, van Vollenhoven R. Prevalence and comorbidity of relapsing polychondritis. Clin Epidemiol 2016;8:361-2.

7. Horváth $\mathrm{A}$, Páll N, Molnár K, et al. A nationwide study of the epidemiology of relapsing polychondritis. Clin Epidemiol 2016;8:211-30.

8. Mathian A, Miyara M, Cohen-Aubart F, et al. Relapsing polychondritis: a 2016 update on clinical features, diagnostic tools, treatment and biological drug use. Best Pract Res Clin Rheumatol 2016;30:316-33. 
9. Arnaud L, Devilliers H, Peng SL, et al. The relapsing polychondritis disease activity index: development of a disease activity score for relapsing polychondritis. Autoimmun Rev 2012;12:204-9.

10. Lekpa FK, Chevalier X. Refractory relapsing polychondritis: challenges and solutions. Open Access Rheumatol 2018;10:1-11.

11. Hazra N, Dregan A, Charlton J, et al. Incidence and mortality of relapsing polychondritis in the UK: a population-based cohort study. Rheumatology 2015;54:kev240-7.

12. Ferrada MA, Grayson PC, Banerjee S, et al. Patient perception of disease-related symptoms and complications in relapsing polychondritis. Arthritis Care Res 2018;70:1124-31.

13. Dion J, Costedoat-Chalumeau N, Sène $\mathrm{D}$, et al. Relapsing polychondritis can be characterized by three different clinical phenotypes: analysis of a recent series of 142 patients. Arthritis Rheumatol 2016;68:2992-3001.

14. Puéchal $X$, Terrier B, Mouthon L, et al. Relapsing polychondritis. Joint Bone Spine 2014;81:118-24.

15. Michet CJPost TW, ed. Clinical manifestations of relapsing polychondritis. Waltham, MA: UpToDate, 2018.

16. Janin A, Piette JC, Courtin P. [Relapsing polychondritis and cartilage]. Rev Rhum Mal Osteoartic 1991;58:283-6.

17. Le Besnerais $\mathrm{M}$, Arnaud L, Boutémy $\mathrm{J}$, et al. Aortic involvement in relapsing polychondritis. Joint Bone Spine 2018;85:345-51.

18. Pallo PAO, Levy-Neto M, Rodrigues Pereira MR, et al. Relapsing polychondritis: prevalence of cardiovascular disease and its risk factors, and general disease features according to gender. Rev Bras Reumatol 2017;57:338-45.

19. Leroux G, Costedoat-Chalumeau N, Brihaye B, et al. Treatment of relapsing polychondritis with rituximab: a retrospective study of nine patients. Arthritis Rheum 2009;61:577-82.

20. Moulis G, Pugnet G, Costedoat-Chalumeau N, et al. Efficacy and safety of biologics in relapsing polychondritis: a French national multicentre study. Ann Rheum Dis 2018;77:72-78.

21. THT L, Far N, Young AL. Rapid corneal thinning and perforated ulcerative keratitis in a patient with relapsing polychondritis. Eye Vis 2017;4.

22. Kent PD, Michet CJ, Luthra HS. Relapsing polychondritis. Curr Opin Rheumatol 2004;16:56-61.

23. Filho AL, VV daSJ, Montenegro Carvalho JP. The nasal reconstruction of a patient with relapsing polychondritis. JSM Head Face Med 2017;2.

24. Lang-Lazdunski L, Hvass U, Paillole C, et al. Cardiac valve replacement in relapsing polychondritis. A review. J Heart Valve Dis 1995;4:227-35.

25. Buckley LM, Ades PA. Progressive aortic valve inflammation occurring despite apparent remission of relapsing polychondritis. Arthritis Rheum 1992;35:812-4.

26. Francès $\mathrm{C}$, el Rassi R, Laporte JL, et al. Dermatologic manifestations of relapsing polychondritis. A study of 200 cases at a single center. Medicine 2001;80:173-9.

27. André MF, Piette JC, Kémény JL, et al. Aseptic abscesses: a study of 30 patients with or without inflammatory bowel disease and review of the literature. Medicine 2007;86:145-61.

28. Papo T, Wechsler B, Bletry O, et al. Pregnancy in relapsing polychondritis: twenty-five pregnancies in eleven patients. Arthritis Rheum 1997;40:1245-9.
29. Belot A, Duquesne A, Job-Deslandre C, et al. Pediatric-onset relapsing polychondritis: case series and systematic review. $J$ Pediatr 2010;156:484-9.

30. Fonseca AR, de Oliveira SK, Rodrigues MC, et al. Relapsing polychondritis in childhood: three case reports, comparison with adulthood disease and literature review. Rheumatol Int 2013;33:1873-8.

31. Rohena-Quinquilla IR, Mullens F, Chung EM. MR findings in the arthropathy of relapsing polychondritis. Pediatr Radiol 2013;43:1221-6.

32. Torrelo A. CANDLE Syndrome as a paradigm of proteasome-related autoinflammation. Front Immunol 2017;8:927.

33. Thaiss WM, Nikolaou K, Spengler W, et al. Imaging diagnosis in relapsing polychondritis and correlation with clinical and serological data. Skeletal Radiol 2016;45:339-46.

34. Faix LE, Branstetter BF. Uncommon CT findings in relapsing polychondritis. AJNR Am J Neuroradiol 2005;26:2134-6.

35. Yamashita H, Takahashi H, Kubota K, et al. Utility of fluorodeoxyglucose positron emission tomography/computed tomography for early diagnosis and evaluation of disease activity of relapsing polychondritis: a case series and literature review. Rheumatology 2014;53:1482-90.

36. Imanishi $\mathrm{Y}$, Mitogawa $\mathrm{Y}$, Takizawa $\mathrm{M}$, et al. Relapsing polychondritis diagnosed by Tc-99m MDP bone scintigraphy. Clin Nucl Med 1999;24:511-3.

37. Nakano K, Aritomi T, Ohkubo N, et al. Relapsing polychondritis diagnosed by fusion images of gallium-67 uptake on computed tomography and single-photon-emission computed tomography. Arthritis Rheumatol 2017;69:2406.

38. Jeon $\mathrm{CH}$. Relapsing polychondritis with central nervous system involvement: experience of three different cases in a single center. $J$ Korean Med Sci 2016;31:1846-50

39. Kim IK, Kim MS, Choi YS, et al. Anesthetic experience of a patient with relapsing polychondritis -A case report. Korean $\mathrm{J}$ Anesthesiol 2012;63:465-8.

40. Tanaka TT, Furutani HF, Harioka TH. Anaesthetic management of a patient with relapsing polychondritis undergoing laparoscopic surgery. Anaesth Intensive Care 2006;34:372-4.

41. Raida BS, Yosra C, Faten F. A relapsing polychondritis and malignancies: a case report and review of literature. J Dermatol Res Ther 2016;2:041.

42. Bin Ismail MA, Lim RHF, Fang HM, et al. Ocular Autoimmune Systemic Inflammatory Infectious Study (OASIS)-report 4: analysis and outcome of scleritis in an East Asian population. J Ophthalmic Inflamm Infect 2017;7:6.

43. Lichauco JJ, Lauer S, Shigemitsu HH. Orbital mucosaassociated lymphoid tissue (MALT)-type lymphoma in a patient with relapsing polychondritis. Arthritis Rheum 1713;2001:1713-5.

44. Matzkies FG, Manger B, Schmitt-Haendle M, et al. Severe septicaemia in a patient with polychondritis and sweet's syndrome after initiation of treatment with infliximab. Ann Rheum Dis 2003;62:81-2. 